\title{
The Types of Meaning in Coca Cola Company Advertisement
}

\author{
I Gusti Ayu Agung Dian Susanthi ${ }^{1}$, Ayu Diana Pramita ${ }^{2}$ \\ \{diansusanthi@warmadewa.ac.id ${ }^{1}$, dianapramita@gmail.com²\} \\ ${ }^{12}$ Faculty of Letters, Universitas Warmadewa Denpasar-Bali, Indonesia
}

\begin{abstract}
This study aims to analyze the types of meanings and massage constructed in Coca Cola advertisement. The theory applied is taken from Leech entitled Semantics, the study of meaning the second edition. The data source of this study is taken from fifteen of brochures coca cola. The data are collected by download the brochures and all of the data are noted. Then, the data are classified based on types of meanings and the messages constructed. In addition, the data is analyzed by qualitatively using a qualitative descriptive approach. Based on the result of analysis, it was found that there are seven types of meanings. They were conceptual, connotative, social, reflected, affective, thematic, and collocative meaning. To sum up, the messages constructed were Coca Cola is the best products in the world with ingredients that are very safe to consume. Its products are spread all over the world at affordable prices.
\end{abstract}

Keywords - Coca cola, advertisement, seven types of meaning

\section{Introduction}

Communication has a very important role in marketing product or service. In our daily life, the greatest media in selling and promoting the product or service to a large number of people is an advertisement. It can be divided into two aspects they are an electronic advertisement and printed advertisement. The electronic advertisement consists of electronic media such as television, internet, radio, etc. The printed advertisement consists of printed media such as magazine, newspaper, brochure, billboard, etc.

The advertisement is a message designed to promote a product or service on an idea. Large business firms use an advertisement to sell to buy their product to create favourably image of their company/products. It is comparatively cheapest and fastest way to inform a large number of people about product or service for sale and persuade them to buy. Coca cola advertisement has a special purpose. The language in the advertising text of coca cola has different language forms used in our daily lives. Usually not formal, sentences used to vary and contain meaning and words of interest. In addition to interesting language, there is action in the video that aired on the advertisement, can also make the product enthusiasts become interested to consume.

Nowadays, advertising uses every possible media to get its message through. It can be through via television, print (newspapers, magazines, journals etc), radio, press, internet, direct selling, hoardings, mailers, contests, sponsorships, posters, clothes, events, colours, sounds, 
visuals, and even people (endorsement) (The UK Advertising Association). Language conveys its dictionary meaning, connotations beyond the dictionary meaning, information about the social context of language use, speaker's feelings and attitudes rubbing off of one meaning on another meaning of the same word when it has two meanings and meaning because of habit occurrence. Broadly talking about 'meaning' means that the sum total of communicated through language. Words, Phrases, and sentences have meanings which are studies in semantics. There are seven types or ingredients giving primacy to conceptual meaning ${ }^{[1]}$.

Referring to this present study, some researchers have conducted the same study, such as in research [2] entitled "A Semantic Analysis of Denotative Meaning in Kudung Doa Song by Sunan Kalijaga". Based on the analysis, their results showed that Kidung "Rumekso ing Wengi" is a kidung doa composed by Sunan Kalijaga in his journey/dakwah to spread Islam religion in Javanese Island, He uses this song (kidung) as the medium for dakwah. And the second song Kidung Lingsir wengi was composed by Sunan Kalijaga, when he conducted a meditation in the midnight after he did the midnight prayer/tahajud. He composed this song used for worship to ALLAH SWT. In Kidung Rumekso ing wengi, Ilir-ilir and Kidung Lingsir Wengi, Sunan Kalijaga used simple word to his listener, because it would be more affective to deliver the message to the listener. In first song also contain the religious messages that we should be aware of our life, when we want to have a better lives, the comfortable life, the prosperity and the protection for our body, we must stay in the path (Islam), and obey to ALLAH SWT (Syariat). Because our life, destiny, fortune, etc. has in ALLAH SWT controlled. In the second song contains the messages the Moslem should did the mid-night prayer/tahajud and the early morning prayer, because that time is very special time for Moslem compare to another prayer time, the angle watched our prayer in this time, and we can more close face ALLAH SWT in this time. Furthermore, ${ }^{[3]}$ the similar study, entitled "Types and Functions of Associative Meanings in the Opening Statement Used by the Host of Mata Najwa Talk Show", the results showed that the types of associative meaning in this research are connotative meaning (25 data), stylistic meaning (1 data), affective meaning (5 data), reflected (21 data), and collocative meaning ( 0 data). This research also find out the functions of associative meaning; connotative meaning is used to assert the hearer about the speaker's ideas; stylistic meaning is used to show the expression of the speaker, expressed through the style of the use of words, affective meaning is used to express the feeling of the speaker; reflected meaning is used to present the new sense of word. The function of associative meaning in this research mostly used is representative. However, this study is different from the present study, since this study only analyze one of types of meaning in Semantics, and it wasn't complete. Thus, based on the explanation and the latest related studies above, this present study aims analyzed the types of meaning in coca cola advertisements and also analyze the message constructed in coca cola advertisement.

\section{Method}

The data were taken from some brochures. Coca-Cola brochure was chosen because this brochure is unique and these brochures consist of meaning and have very deep meaning to a customer who saw them. There were fifteen of brochures chosen from 2015 to 2017. Those data displayed interesting videos through television advertising program, by describing the conditions and situations and different flavours. The data were collected by downloading from the internet, and then the collected data were classified. After the required data was collected, 
and then analyzed according to the types of meaning found in coca cola brochures. The method that was used in analyzing the data was a descriptive method.

\section{Results And Discussion}

The types of meaning in coca cola advertisement are conveyed in the forms of word, phrase, and sentence. These forms were found in the brochure, pamphlets, and some videos commercial advertisement. The discussion below presents the types of meaning in each of those parts.

\section{A. Conceptual Meaning}

The conceptual meaning is the literal meaning of the word indicating the idea or concept it refers to. It deals with the core meaning expression. Those are explained in the included images and analysis below.

1. 'Come on - let's have a 'COKE'!

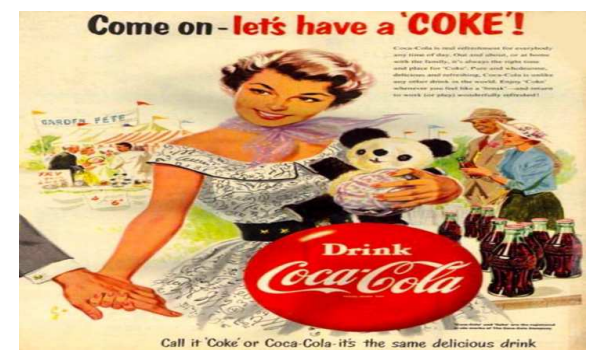

Fig. 1. Conceptual Meaning

The phrase analysis of 'Come on - let's have a' COKE'! in the above brochure, contains a denotative meaning which emphasizes the logical meaning to invite to enjoy a fresh drink. In the first sentence which stated 'coke' or coca cola, has the same intention which expresses 'delicious drink', contains a meaning that emphasizes the equation that either 'coke' or 'coca cola' is a soft drink.

2. 'Continous quality is quality you Trust'

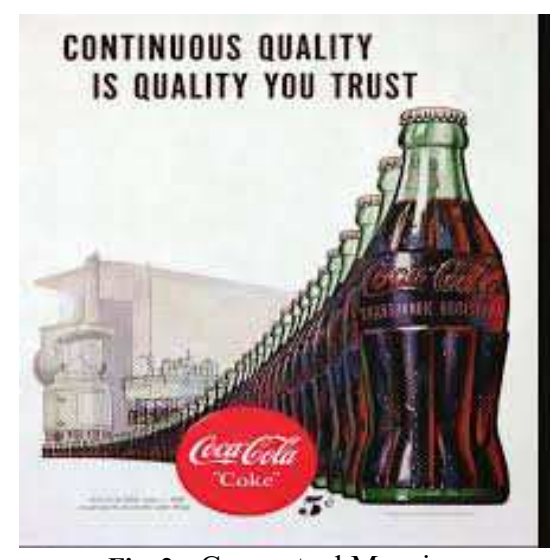

Fig. 2. Conceptual Meaning

The phrase on the second brochure 'continuous quality is quality you trust'. The word 'quality' affirms the consumer's confidence in this carbonated soft drink product to always be 
the best in maintaining the taste and quality of this product. For the figure on the brochure, there are many lined bottles which means that the coca cola in producing always amounts to a lot because the product of coca cola is in great demand and favoured by consumers. In this brochure there is also a product identity, which says the phrase 'quality is trust' is a sense of quality as the source of identity or basic concepts in this product to give confidence in service and safety in consuming this product.

\section{B. Connotative Meaning}

The connotation is a real-world value a speaker associated with an expression. In other words, it is the meaning above the conceptual meaning and it may vary according to culture, background or society. The following explanation gives information about connotative meaning and sample brochures.

1. 'The pause that refreshes'

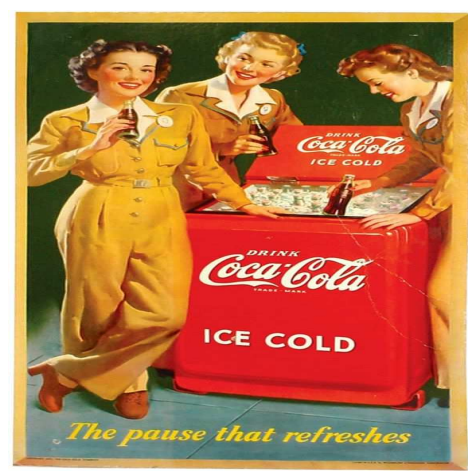

Fig. 3. Connotative Meaning

The phrase 'the pause that refreshes' contains connotative meaning because in the brochure there are pictures of three women who express their happy moments while relaxing or taking a break, so the brochure display here reflects the meaning of conditions and situations in the female character. In the brochure, there is the phrase 'the pause that refreshes' this means that the picture and sentence in this brochure, invites us how to feel the freshness of carbonated drinks without any limits or pauses, so the freshness at all times.

2. 'So easy to take home, the six-bottle carton'

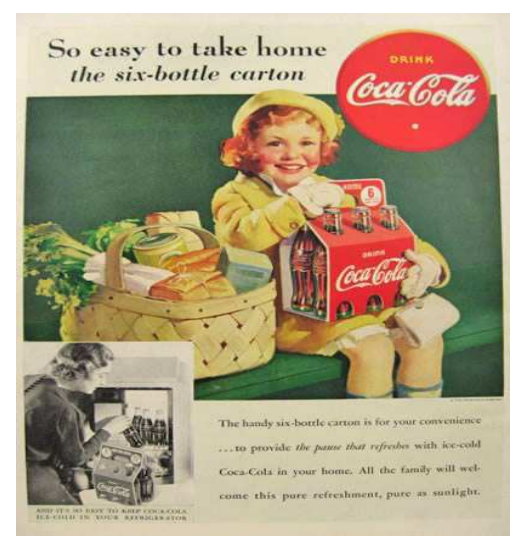

Fig. 4. Connotative Meaning 
Furthermore, the phrase 'It is easy to bring home the six-bottle carton' described in the brochure is a connotative sense, which in the brochure is shown as a little girl carrying a carton of coca-cola containing six bottles, this is the communicative value of the phrase according to what is in the pack, it is very easy to carry everywhere, and even a little girl can carry the packaging. From connotative meaning, there is the word 'girl' or 'woman' where there are some characteristics of woman that is physical, psychological, and social. In the phrase 'The six bottle cartons are practically four conveniences ... to provide that refreshes with ice-cold. Coca-cola in your home. All the families will welcome this pure refreshment, pure as sunlight' also contains the connotative meaning that is the communicative value of expression over and above its purely conceptual content. In this brochure there is a sentence 'to provide that refreshes with ice-cold' which means that when it is consumed, it is very suitable with ice cubes, because it feels very refreshing especially in the summer and when the sun is very hot, it can be served in various events, very easily presented with only added ice cubes.

C. Social Meaning

Social meaning is related to the situation in which an utterance is used. It is concerned with the social circumstance of the use of a linguistic expression. The decoding of a text is dependent on our knowledge of stylistic and other variations of the language. The following description of social meaning and sample brochures is explained as follows:

1. 'happiness coca cola'

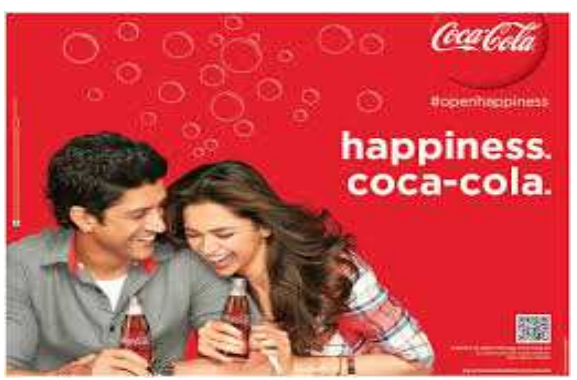

Fig. 5. Social Meaning

A phrase 'happiness coca cola' means being happy with coca cola, because it means that coca cola always brings happiness for anyone who drinks it and in any situation, the social meaning in the sentence in this brochure refers to the existence of some words or words as dialects. The sentence in this brochure also invites the social environment to always be happy. In the brochure, there is the phrase 'happiness of coca cola', the meaning of the sentence in this brochure is that there is a sense of happiness when it is drunk, because it feels so refreshing when the weather is very suitable for consumption, and when drinking it other than fresh feeling and feeling of happiness that can be felt to eliminate adamant thirst.

2. 'Great Taste Runs in The Family'

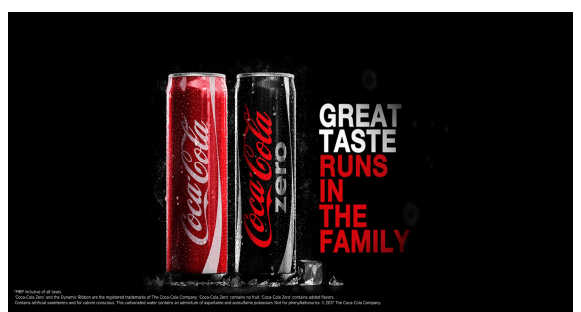

Fig. 6. Social Meaning 
In the phrase 'Great Taste Runs in The family' in coca cola advertisement brochure, there is a social meaning associated with the situation in which an utterance is used. In the words 'Runs' and 'The Family', there is a snippet of words or languages about the social context used for our knowledge of language styles and other language variants. In this brochure there is a sentence 'great taste runs in the family' which means extraordinary taste in the family because when gathering with the family is a very pleasant thing, sharing happiness with the family is jokes and laughter, not to forget presenting food that is very fast and accompanied by cold drinks that are sparkling. Therefore, drinks are often served at various events during family gatherings

D. Affective Meaning

Affective meaning is the aspects of meaning which "reflects personal feelings of the speaker, includes the attitude of the listener or his attitude to something the listener was talking about. However, Leech's includes as in the case of social meaning, not only difference in the use of words or lexemes but also factors of intonation and voice-timber referred to as tone of voice. Below is an explanation of affective meanings and examples of coco cola brochures, as follows:

1. 'New Coca cola Life'

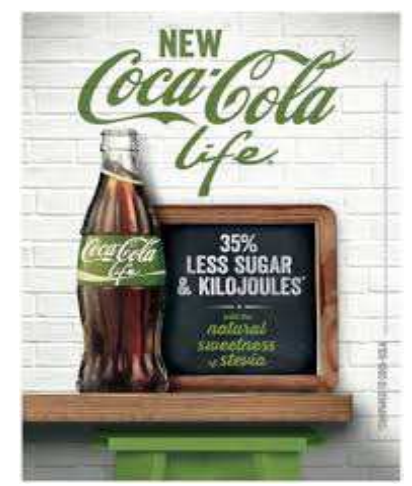

Fig. 7. Affective Meaning

The brochure in affective meanings there is a phrase 'New coca cola life' and affective meanings are aspects of meaning that reflect the personal feelings of the author including his readers. The word 'new' and 'life' suggest that the product expresses new life. The author in this sense invites the reader to consume soft drinks and feel the sensation of starting something new. In this brochure, there is the phrase 'New Coca-cola life' which means that it can also mean each gulp when it is drunk, it feels like feeling something new, the feeling of freshness that it is felt maybe something different, like when we are born again and step into a new life. 


\section{2. 'Hello..I'm 'Coca cola' known, too, as 'Coke'}

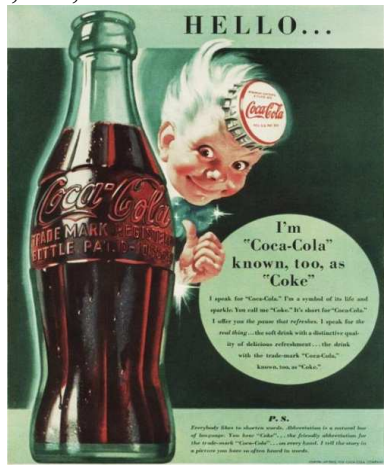

Fig. 8. Affective Meaning

For the phrase 'Hello..I'm' Coca-cola 'known, too, as' Coke' explains the expression of his personal feelings from the author as well, the author also introduces the product through this brochure. Therefore, for those who read the brochure there is a sense of wanting to know the meaning of the sentence, here there is a difference in the word intonation. The word 'coca cola' is better understood than the 'coke', but both actually mean soft drinks. In this brochure, there is a sentence 'Hello. I'm Coca-Cola' is also known', too, as' coke', which means that this product introduces itself with a simple name in the simpler mention of 'coke'. Like the words 'coca cola' and 'coke' in the brochure, this means the same but the rate of mention is different, westerners there call 'coke' more often, while the eastern ones are more often called 'coca cola' drinks or soft drinks.

\section{E. Reflected Meaning}

Reflective meaning is the meaning which arises in cases of multiple conceptual meaning when one sense of a word form is part of our response to another sense. Reflected meaning is communication through association with another sense of the same expression. Below is an explanation of reflected meanings and examples of coco cola brochures, as follows:

1. 'Get your own customized bottle', and 'Do you want coke bottle with your name on it?'

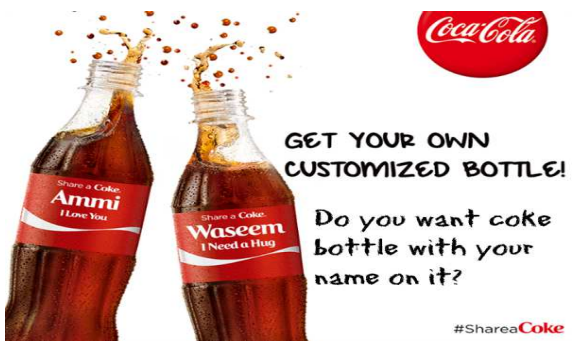

Fig. 9. Reflected Meaning

The phrase 'Get your own customized bottle' in this reflective meaning is a phenomenon where one word or phrase is associated with more than one meaning or meaning. The word 'bottle' in the sentence above shows that the word can mean a lot depending on the order of sentences and the purpose of the sentence. A word can also form part of our response to another sense. In this brochure the phrase 'do you want to coke bottle with your name on it?' this means that the innovation made by this product is very good, can include the name of the consumer on the bottle packaging. This is a surefire way to attract consumers because of more and more people like this carbonated beverage. 
2. 'Have a Coke with Me'

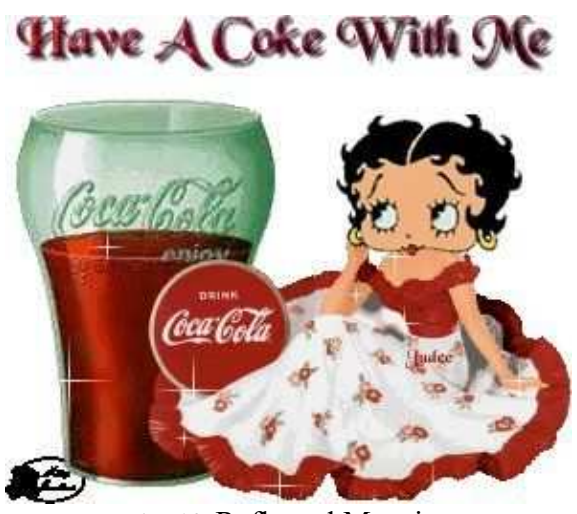

Fig. 10. Reflected Meaning

The second brochure with the phrase 'have a coke with $m e^{\prime}$ sounds strange, for the use of the word 'have' in this sentence from the word it has one meaning but its meaning may have many other significance and understandings, and it depends on the use of the word 'have' for the past, present or future because reflective meaning is a phenomenon of a word or phrase that is linked to more than one meaning or meanings. The brochure has the phrase 'have a coke with me' this means enjoying this soft drink with me, so it can be enjoyed together with anyone and the other purpose is also the word 'have' means to have a sense of freshness with me. It was concluded that the meaning of the sentence above is a feeling of togetherness that is very good among others.

\section{F. Collocative Meaning}

Collocative meaning is a type of meaning that offers association of a word with other meaning of the world in certain environments. Collocation is a broad term which describes words that often appear together in common usage, either spoken or in text. Collocative meaning refers to associations of a word because of its usual or habitual co-occurrence with certain types of words. Below is an explanation of reflected meanings and examples of coca cola brochures, as follows:

1. 'Great Coca cola taste', 'Zero Calories, Zero Sugar'

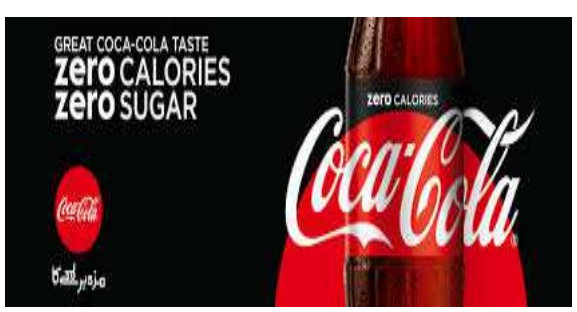

Fig. 11. Collocative Meaning

The sentence in the coca cola brochure 'Great coca cola taste' means this product has a feeling that need not be doubted, the sweet and fresh taste is the mainstay. In this sentence, there is a collocative meaning that is meant to occur together with certain words. In this brochure there is a sentence that the mention of one word 'Zero calories, Zero sugar' means that both for those who do not like sweet, good for those who run a diet program, all people can consume, the taste is also very refreshing, as a very thirst reliever.

2. 'Share Coke....Share feeling' 


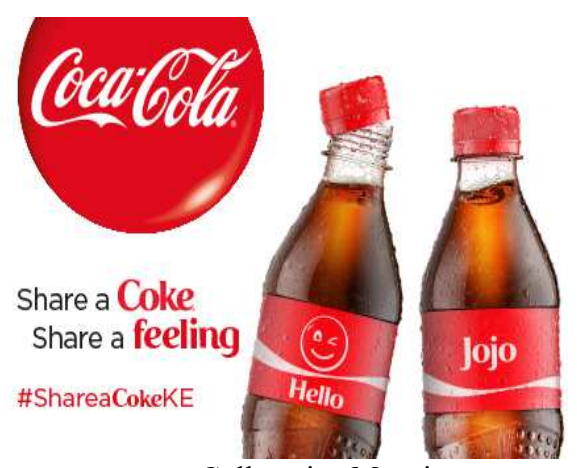

Fig. 12. Collocative Meaning

The phrase of the brochure 'Share Coke .... Share Feeling' means to promote its products use the word 'share' with the intention of sharing to anyone, whether sharing a drink or sharing the taste, so the collocative meaning here is the meaning communicated through the words that go along with other words. In the brochure, there are the words 'coke' and 'feeling' which means that there is a sense that can be shared with us drinking this soft drink. Sharing joy, happy with friends, friends or even partners, the meaning of collocative is very appropriate for the sentence in the brochure, because there is one concurrent word in one sense.

\section{G. Thematic Meaning}

Thematic meaning is the meaning that is communicated by the way in which the speaker or writer organizes the message, in term of the order, focus, and emphasis. Various parts of the sentence also can be used as subject, object, or complement to show prominence. Below is an explanation of thematic meanings and examples of coca cola brochures, as follows:

1. 'King Size....Puts You at Your Best'

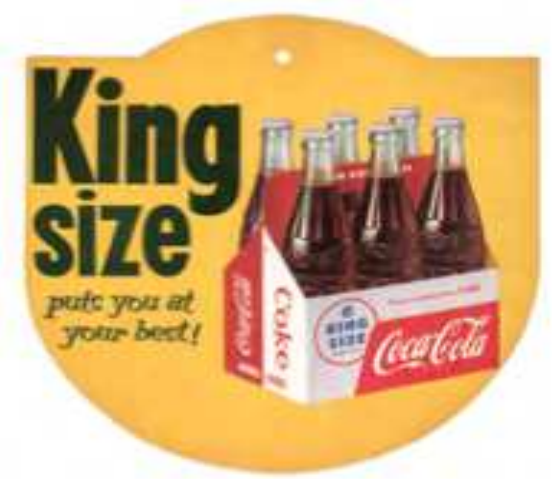

Fig. 13. Thematic Meaning

In this brochure, there is the phrase 'King Size ... Puts you at your best'. The meaning of the sentence is this coca cola product has an appropriate size to enthusiasts of soft drinks because coca cola products are produced for bottle packaging that has several sizes, so it varies in size options. Thus, the thematic meaning is contained in the sentence, because what is communicated in the manner in which the message is governed in terms of order and emphasis. 


\section{2. 'Sign of Good Taste'}

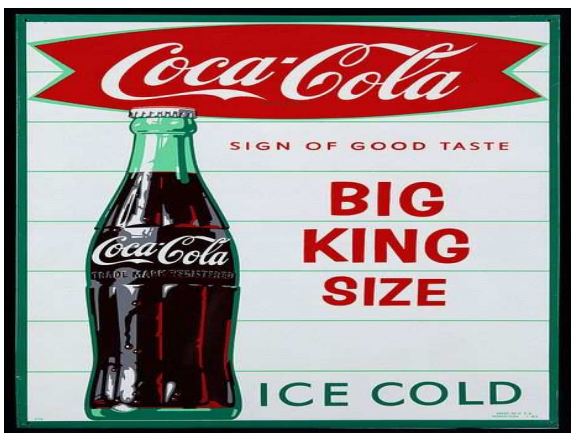

Fig. 14. Thematic Meaning

The next brochure in the phrase 'sign of good taste' in this thematic meaning refers to what the speaker or the author communicates in the corresponding message to focus on emphasis. Therefore, the sentence above is part of a sentence that can be used as subject, object, or complement to indicate conformity to a sentence. In this brochure, there is the phrase 'sign of good taste' which the meaning of this sentence gives a different and tasty taste because the quality of this product has been worldwide. Many people like the taste and for the category of soft drinks there are four variants that are produced in addition to the sponge coca cola, and the fruit flavour is two categories, strawberries and oranges, so the taste can be chosen according to the customer's desires.

\section{Conclusion}

Based on the analysis above, it can be concluded that the types of meaning are found in the coca cola of brochure advertisement. The types of meaning are in the form of word, phrase, and sentence. The type of meaning found in the sentence of a brochure is the conceptual meaning, connotative meaning, social meaning, affective meaning, reflective meaning, collocative meaning, and thematic meaning. In this case, these meaning are intended to be able to affect the readers and promoted advertisement. The combination of language styles or phrases listed in the brochure can have an effect on those reading it, as they know what the phrases are in the brochure and the product picture and there are also pictures of some people who are enjoying Coca-Cola products, so consumers can imagine and feel freshness when consuming soft drinks. Coca-Cola products not only produce soft drinks, but there are several categories of drinks, namely: juice, milk, tea, energy drinks, and mineral water. For that very easy to sell this product, the price is affordable and very easy to get.

\section{Reference}

[1] G. Leech, Semantic: The Study of Meaning. New York: Penguin Books, 1974.

[2] S. N. Agung, A. Wibowo, and T. T. R. Wilujeng, "A Semantic Analysis of Denotative Meaning in Kudung Doa Song by Sunan Kalijaga,” Jurnal Ilmiah Bahasa dan Sastra, vol. 3, no. 1, pp. 1$20,2016$. 
[3] Nelvia, R. N. Rosa, and Fitrawati, "Types and Functions of Associative Meanings in the Opening Statement Used by the Host of Mata Najwa Talk Show," E-Journal of English Language and Literature Volume, vol. 8, no. 1, 2019. 